\title{
A Study of College English Writing Classes through Consciousness-raising
}

\author{
Runjiang Xu \\ English Department, Zhenjiang Watercraft College of PLA, Zhenjiang, China \\ Email: xurunjiang_88@hotmail.com \\ Qi Pan \\ English Department, Zhenjiang Watercraft College of PLA, Zhenjiang, China
}

\begin{abstract}
By consciousness-raising we mean the deliberate attempt to draw the learner's attention specifically to the formal properties of the target language. It focuses its attention on teaching process and students' activeness, so it can be well applied to teaching of college English writing. This study indicates that consciousness-raising provides a guideline for improving teaching of college English writing and plays a significant role in enhancing students' writing ability.
\end{abstract}

Index Terms - consciousness-raising, English writing classes, awareness

\section{INTRODUCTION}

Through long-time teaching practice, college English teachers have tried a lot to cultivate students' language competence, aiming at transferring language skills and relevant cultural knowledge to students. In order to lay a good foundation of self-learning for students, the importance of Consciousness-Raising (C-R) have been recognized and advocated popularly by more and more college teachers and researchers in discussion of language competence. This study is set in simplicity to find out whether the pursuit of Consciousness-Raising can be helpful to develop English writing proficiency and reach improvement in College English teaching.

\section{THEORIES OF CONSCIOUSNESS-RAISING}

\section{A. Meaning of Consciousness-raising}

The most widely cited explanation of "consciousness" in SLA literature is given by Schmidt (1990), who distinguishes "consciousness" in three senses: consciousness as awareness, consciousness as intention and consciousness as knowledge. In both common usage and theoretical treatments of the topic, consciousness is commonly equated with awareness, and according to Schmidt, consciousness as awareness can be further divided into 3 levels: Level 1 is perception, which implies mental organization and the ability to create internal representations of external events", but which is "not necessarily conscious and subliminal perception is possible". Level 2 is noticing or focal awareness, by which "stimuli are subjectively experienced", and which "can be operationally defined as availability for verbal report, subject to certain conditions". Level 3 is understanding, which means after noticing, we can "analyze", "compare", "reflect", "comprehend" etc. the object of noticing(Schmidt, 1990, P11). In fact, C-R, earlier connecting with the idea of noticing, attempts to raise the awareness of language on learners by means of providing certain language input and activity. Such language awareness activities have grown in importance in teaching, and now represent a wide range of choices that can be made (Sharwood Smith, 1991).

As for C-R, Hawkins (1984) mentions it involves challenging pupils to ask questions about language, encouraging learners to gather their own data outside school, and helping learners to develop a growing insight into the way language works to convey meaning". Rutherford and Sharwood Smith (1985) define C-R as "by consciousness-raising we mean the deliberate attempt to draw the learner's attention specifically to the formal properties of the target language." (1985) Therefore, C-R is a mental attribute which develops through paying attention to language in use, and which enables language learners to gradually gain insights into how languages work (Brian Tomlinson, 2003). It differentiates from traditional language teaching pattern which focuses on teachers' speech in class. C-R emphasizes the development of enhanced awareness in language learners to the acquisition of a language. The key point is that teachers are supposed to be helpful to discover language by learners themselves.

\section{B. Previous Study of Consciousness-raising Approach}

C-R lies a lot on cognitive psychology, which involves the subject of metacognition. Flavel (1976) first gives the term and refers to it as our awareness of the learning process. Students without metacognitive approaches are essentially learners without direction and ability to review their progress, accomplishments and future learning directions $\left(\mathrm{O}^{\prime}\right.$ Malley et al, 1985). The cognitive focus on language awareness also echoes with research of explicit and implicit 
learning. Accordingly, rules, whether they are teacher-made or devised from a textbook, offer the opportunity for intellectual or explicit learning, while textual input encourages intuitive and implicit learning. It once remains controversial whether learners learn implicitly or explicitly but explicit teaching of second language is with the similar meaning of C-R. Since college students have reached certain level of language study, explicit learning may aid them in developing implicit learning by noticing the gap between what they have achieved from the input and the current state from the output. Thus, we cannot ignore the importance of explicit knowledge in second language acquisition which asks to facilitate C-R teaching tasks.

\section{IMPLICATIONS OF CONSCIOUSNESS-RAISING IN COLLEGE ENGLISH WRITING CLASSES}

English writing has been a hot topic in college English teaching and remains an area of many researches and debates. Competent writing is frequently accepted as being the most challenging language skill to be acquired. Few people write spontaneously, and few feel comfortable with a formal writing task intended for the eyes of someone else. Its complex, multifaceted nature set a strict standard for learners to express their ideas, so teachers find it difficult to carry out some effective strategies on improving students' writing.

$\mathrm{C}-\mathrm{R}$ advocates creating a language environment for learners to discover English features on their own in order to develop their capability in writing. This happens to be the same view with the processing writing method in other studies. Beside, C-R aims to arouse learners' attention irrespective of the age, maturity and proficiency of individual. It seems more reasonable to adopt $\mathrm{C}-\mathrm{R}$ in a class of English writing to make active participation of every member in the class.

\section{A. Methodology}

The study started from one composition task from one class of 30 sophomores in Zhenjiang Watercraft College. Although the target students are not in a large number, to some extent they are typical among college English learners.

The topic was given below:

Direction: why is it so difficult to define happiness and how to achieve it?

Happiness is always considered important to human beings. But why is it so difficult to define happiness and why are the definitions of happiness so different among people?

After class, grading job was done and problems were listed:

a. From the aspect of grammar. It is very common for two kinds of errors: gender and tense. Students usually mistake adjectives for nouns and vice versa, for example, "don't eager to something unreality", "is depend on yourself", "what is the mean to happiness", etc. Some of the errors can be corrected by students after teacher tick such errors out for they write down subconsciously, but some cannot arouse their awareness for they write down without too much consideration. It results to increasing job for teachers to mark their compositions but end in less influence on their writing proficiency. Tense is another factor which cannot be ignored. It is not for their low master of tense but for their confusion of tense in a piece of writing. The majority of compos ions collected indicate students overdo a distinction in time description but it seems the more specific they refer to, the more confused they choose the tense.

b. From the aspect of vocabulary. Through data collected, it embodies that students have gained a large vocabulary. Problems come out in the area of collocation and accuracy. For collocation errors, expressions like "in the day", "take advantage at", "survive from the disaster" are found common in writing. For the accuracy part, expressions like "feel disappointing/disappointed", "importanter/ more important", "buy easy/ conveniently" come into appearance. It exposes that vocabulary study stops at the level of memory. In fact, words are the base of writing and collocation can be the key to make an accurate sentence even to compose a whole passage. Therefore, $\mathrm{C}-\mathrm{R}$ in writing is used to ask for attention in this area at least.

c. From the aspect of discourse. It is hard for students to make a good arrangement of text structure and suitable cohesive devices. There are in shortage of transitional devices to connect closely each paragraph in order to avoid writing in stiff way. Besides, some cannot utilize reasonable illustrations to express the theme; some illustrate excessively without reasoning; and some even digress when coming to the end of writing. In general, students lack of awareness in framework.

According to the global scoring standard of CET-4 (College English Test Band 4), the average score of this class was 7.6 with 15 points as the full score.

\section{B. Application of $C$-R Approach in English Writing}

The scores indicate students stay in a low level in English writing. There are several causes that are unavoidable such as the course design, teaching purpose, limited time and, mostly, teaching methods. Teachers in China would like to focus on product writing approach which ignores the active performance of students. So here organize several C-R strategies in order to attract students into active writing class including peer evaluation, group discussion, debate, brainstorming, questions-asking, model composition appreciation, error analysis, word games, etc. Such activities foster students' cognition and their won exploration. Through training for 2 weeks of 4 classes, students were asked to rewrite this composition and graded according to CET-4 again. Generally speaking, students got achievements in writing and the average score reached at 8.6, two of which even got the highest of 12 . The majority of the class improves the writing 
skills in accurate expressions, collocation and grammar. But the discourse cohesive devices were not completely mastered for the time was limited and writing was a long process of practice.

After C-R approach applied in writing teaching, an interview was taken to see the attitudes of students on C-R. During the interview, students welcome to introduce C-R approaches in class and most of them claim that they become to realize writing can be interesting and the learning activities can be designed by themselves. The previous learning methods seem too mechanical and dependent.

\section{DISCUSSIONS}

\section{A. $\quad$ C-R Approach's Influence on Students' Learning}

From the talk with students, it is apparent that C-R influence students' affective state a lot. Previously, writing classes seem monotonous to them and mean a heavy load of writing job to them. They never take mistakes into consideration but feel no other way to write on and on. However, what they repeat is almost the mistakes without the awareness to correct. This kind of writing cannot improve their writing skills but guide them into a trap of a vicious spiral. After introducing C-R into class, students are asked to discover their mistakes by their own or in group work. So the writing class motivates students in writing study. "If asked to identify the most powerful influences on learning, motivation would probably be high on most teachers' lists, and it seems only sensible to assume that learning is most likely to occur when we want to learn" (Marion Williams \& Robert Burden, 2000, p10) Affective factors generally include attitude, anxiety, inhibition, self-esteem, motivation and empathy (Arnold, 2000).

Learner, who has experienced success, will have these attitudes reinforced. Similarly, learners' negative attitudes may be strengthened by lack of success. Through investigation after class, students agree that they now can learn lively and previously they show prejudice in English writing. Actually English writing class can be student-centered by means of several arrangements such group discussion, teachers' guide, essay appreciation, during which students are found less anxiety and get inspired from each other. They focus on the problems in writing, share ideas and cooperate to find answers to the problems. Eventually, they become to accept the new learning method and feel free to communicate with teachers. They learn they are the leading role at class.

\section{B. C-R Approach's Influence on Teachers'Teaching}

In writing instruction, two main approaches are often applied by teachers: the product approach and process approach. By product approach, teachers ask students to pay their attention on the features of model texts and spend much time on developing their ability to produce those features in accuracy. There are usually three steps in this writing method. At the beginning, teachers leave a topic for a composition assignment; and then students are requested to hand a piece of writing in a limited time; finally teachers correct and mark those writing and give feedback next class. For the process approach, students are the center and they are encouraged to create language in order to express their own ideas with their own individual intrinsic motives. Brown (2002) in his research reveals advantages of this writing method: focus on the process of writing that leads to the final written product; help student writers to understand their own composing process; help them to build repertoires of strategies for prewriting, drafting, and rewriting; let students discover what they want to say as the write; encourage feedback both from the instructor and peers. Through this method of writing, students not only become more familiar with the process of writing but also become more accountable in developing writing skills. Apparently, teachers in product approach teaching usually overemphasize the final product of writing and pay little attention to the composing process. The inevitable result is that students practice writing time and time again using stereotyped expressions so as to leave them in low mood even frustration. However, C-R tasks are set in the same purpose with the process approach. Teachers are expected to play roles as guide, facilitator, assessor, partner, communicator, source of information, and organizer. On the one hand, teachers need to promote students' learning initiative by using autonomy and metacognitive strategies. On the other, teachers need to take the responsibility consciously. Only when teachers are metacognitively aware will they make use of efficient strategies at class to motivate students in writing.

\section{CONCLUSION}

As seen in the simple empirical study, the whole class is benefited from the theories of C-R, which raises their language awareness and builds confidence in writing. The overall goal of any strategy training program is to help learners become more successful in their attempts to learn a foreign language (Cohen, 2000). Writing is a complex activity which requires high proficiency in several areas of knowledge and can conversely promote English learning in China (Wang C.M. et al, 2000). It weighs great in the use of grammar, diction, collocation and the appropriateness of sentence. The result of this study is encouraging although the practice time is limited. The future research is indispensable to investigate more at fulfilling C-R approaches in writing class. Nevertheless, it is also hopeful that this research inspires some new thoughts and makes contributions to replicate the study in the area of foreign language acquisition. 
[1] Arnold, Jane. (2000). Affect in Language Learning. Cambridge: CUP.

[2] Brian Tomlinson. (2003). Developing Materials in Language Teaching. London: Continuum Press.

[3] Brown, H.D. (2002) .Principles of Language Learning and Teaching. Beijing: Foreign Language Teaching and Research Press.

[4] Cohen AD. (2000). Strategies in Learning and Using a Second Language. Beijing: Foreign Language Teaching and Research Press.

[5] Flavel. J.H. (1976). Metacognitive Aspects of Problem Solving. In: Resnick L.B. The Nature of Intelligence. NJ: Edbaum.

[6] Hawkins. E. (1984). Awareness of Language: An Introduction. Cambridge: Cambridge University Press.

[7] Marion Williams \& Robert L. Burden. (2000). Psychology for Language Teachers. Foreign Language Teaching and Research Press, 10.

[8] O’ Malley. J., A. Chamort, G. Stewner-Manzanaraes, L. Kupper \& R. Russo. (1985). Learning Strategies used by beginning and Intermediate ESL Students. Language Learning, 21-46.

[9] Rutherford. W. \& Sharwood-Smith. (1985). M. Consciousness-raising and Universal Grammar. Applied Linguistics, 6:276.

[10] Sharwood Smith. (1991). Consciousness-raising and the Second Language Learner. Applied Linguistics 2: 159-169.

[11] Schmidt, R. W.T. (1990). The Role of Consciousness in Second Languae Learning. Applied Linguistics: 11.

[12] Tomlin. R.S. \& Villa. V. (1994). Attention in Cognitive Science and SLA. Studies in Second Language Acquisition, 16: 183-203.

[13] Wang. C.M, Niu. R.Y, \& Zheng. X.X. (2000). Improving English through Writing. Foreign Language Teaching and Research (bimonthly). Vol,32. No.3.

Runjiang Xu was born in Zhenjiang, China in 1984. She receives her M.A. degree in Foreign Linguistics and Applied Linguistics from Jiangsu University, China in 2010.

She is currently a lecturer in English Department, Zhenjiang Watercraft College of PLA, Zhenjiang, China. Her research interests include Second Language Acquisition and Foreign Language Teaching.

Qi Pan was born in Zhenjiang, China in 1987. She received her B.A. degree in English language and literature from Jiangsu University of Science and Technology, China in 2009.

She is currently a tutor in English Department, Zhenjiang Watercraft College of PLA, Zhenjiang, China. Her research interests include Second Language Acquisition and Contrastive Studies of English and Chinese. 